\title{
The influence of chemical structure on the properties in methacrylate-based dentin adhesives
}

\author{
Jonggu Park ${ }^{\mathrm{a}}$, John Eslick ${ }^{\mathrm{a}}$, Qiang Ye ${ }^{\mathrm{a}}$, Anil Misra ${ }^{\mathrm{a}, \mathrm{b}}$, and Paulette Spencer ${ }^{\mathrm{a}, \mathrm{c},{ }^{*}}$ \\ aBioengineering Research Center, School of Engineering, University of Kansas, Lawrence, KS, \\ USA \\ ${ }^{b}$ Department of Civil, Environmental and Architectural Engineering, University of Kansas, \\ Lawrence, KS, USA \\ 'Department of Mechanical Engineering, University of Kansas, Lawrence, KS, USA
}

\begin{abstract}
Objectives-The objective of this study was to investigate the influence of the chemical structure of methacrylate monomers used in dentin adhesives on degree of conversion (DC), water sorption, and dynamic mechanical properties.
\end{abstract}

Materials and methods-Experimental adhesives containing 2,2-bis[4-(2-hydroxy-3methacryloxypropoxy) phenyl]-propane (BisGMA), 2-hydroxyethyl methacrylate (HEMA), and co-monomer, 30/45/25 w/w were photo-polymerized. Ethyleneglycol dimethacrylate (EGDM), diethyleneglycol dimethacrylate (DEGDM), triethyleneglycol dimethacrylate (TEGDMA), 1,3glycerol dimethacrylate (GDM), and glycerol trimethacrylate (GTM) were used as a co-monomer. The adhesives were characterized with regard to DC, water sorption, and dynamic mechanical analysis and compared to control adhesive [HEMA/BisGMA, 45/55 w/w].

Results-DC and water sorption increased with an increase in the number of ethylene glycol units in the monomer. Experimental adhesive containing GDM showed significantly higher storage moduli $(\mathrm{p}<0.05)$ in both dry and wet samples than experimental adhesives containing EGDM or DEGDM. The rubbery moduli of adhesives containing GDM and GTM were found to be significantly greater $(\mathrm{p}<0.05)$ than that of the control. Adhesives containing GTM exhibited the widest tan $\delta$ curves, indicating the greatest structural heterogeneity.

Significance-The hydrophilicity, functionality and size of monomers in dentin adhesives affected the water sorption, solubility, crosslink density and heterogeneity of the polymer network. The experimental adhesives containing GDM and GTM showed higher rubbery moduli, indicating higher crosslink density accompanied by a decrease in the homogeneity of the polymer network structure.

\section{Keywords}

dentin adhesives; structure/property relationships; dynamic mechanical property; degree of conversion; water sorption

(C) 2004 Academy of Dental Materials. Published by Elsevier Ltd. All rights reserved.

*Address all correspondence to Dr. Paulette Spencer, Bioengineering Research Center, School of Engineering, University of Kansas, 1530 W. $15^{\text {th }}$ St., Lawrence, KS 66045, USA. pspencer@ku.edu.

Publisher's Disclaimer: This is a PDF file of an unedited manuscript that has been accepted for publication. As a service to our customers we are providing this early version of the manuscript. The manuscript will undergo copyediting, typesetting, and review of the resulting proof before it is published in its final citable form. Please note that during the production process errors may be discovered which could affect the content, and all legal disclaimers that apply to the journal pertain. 


\section{Introduction}

In 2005, 166 million dental restorations were placed in the United States [1] and clinical studies suggest that more than half were replacements for failed restorations [2]. The emphasis on replacement therapy is expected to increase as concern about mercury release from dental amalgam forces dentists to select alternative materials. Resin composite is the most commonly used alternative [3], but moderate to large composite restorations have higher failure rates, more recurrent caries and increased frequency of replacement as compared to amalgam [2-6]. The primary factor in the premature failure of moderate to large composite restorations is recurrent decay at the margins of the restorations. In class II composite restorations, recurrent decay is most often localized gingivally and is linked to failure of the bond between the tooth and composite and increased levels of the cariogenic bacteria, Streptococcus mutans, at the perimeter of these materials [7-9].

The composite is too viscous to bond directly to the tooth and thus, a low viscosity adhesive must be used to form a bond between the tooth and composite. Acid-etching provides effective mechanical bonding between enamel and adhesive, but bonding to dentin has been fraught with problems. At the most vulnerable margin, i.e. the gingival margin of class II composite restorations there is very little enamel available and thus, the bond at this margin depends on the integrity of the adhesive seal formed with dentin [10-11] In vitro and in vivo studies have suggested that several factors inhibit the formation of a durable adhesive/dentin bond. These factors [12-16] include: (1) adhesive phase separation; (2) water sorption and hydrolysis of the adhesive polymer; (3) degree of conversion of monomer to polymer; (4) mechanical properties; and (5) polymer network structure.

Current dentin adhesive system typically consist of monomers, initiators, solvents, inhibitors or stabilizers and sometimes inorganic fillers [17]. The monomers are a particularly critical since polymerization of the monomers produces a crosslinked matrix that provides chemical/ thermal stability and mechanical strength. Monomer selection exerts considerable influence on the properties, durability and behavior of dentin adhesives in the wet, oral environment. Although numerous monomers have been investigated [17-21] the lack of dentin adhesives that are both effective and durable continues to be a major problem with the use of composites in direct restorative dentistry.

The objective of this study was to investigate the influence of the chemical structure of methacrylate monomers used in dentin adhesives on the following properties: degree of conversion, water sorption, solubility, and dynamic mechanical properties. These results elucidate critical structure/property relationships for methacrylate monomers and provide vital information for future development of durable dentin adhesives.

\section{Material and Methods}

\subsection{Materials}

Experimental adhesives containing bisphenol-A diglycidyl ether dimethacrylate (BisGMA, Polysciences, Warrington, PA), 2-hydroxyethyl methacrylate (HEMA, Acros Organics, NJ), and co-monomer, at 30/45/25 w/w were polymerized with visible light and compared to control adhesives [HEMA/bisGMA, 45/55 w/w]. Ethyleneglycol dimethacrylate (EGDM), diethyleneglycol dimethacrylate (DEGDM), triethyleneglycol dimethacrylate (TEGDMA), 1,3-Glycerol dimethacrylate (GDM), and glycerol trimethacrylate (GTM) were used as a comonomer (all co-monomers were from Aldrich, Milwaukee, WI). The chemical structures of monomers used in this study are given in Fig. 1. The following three-component visible light photoinitiators (all from Aldrich, Milwaukee, WI) were used in this work: camphoroquinone (CQ, $0.5 \mathrm{wt} \%$ ), ethyl-4-(dimethylamino)benzoate (EDMAB, $0.5 \mathrm{wt} \%$ ) 
and diphenyliodonium hexafluorophosphate (DPIHP, $0.5 \mathrm{wt} \%$ ) without further purification [22]. The concentration of the photoinitiator component is calculated with respect to the total amount of monomer. All materials were used as received.

\subsection{Sample preparation and degree of conversion}

Mixtures of monomers/photoinitiators were prepared in a brown glass vial in the absence of visible light. To achieve a homogeneous mixture, the solutions were stirred at room temperature for $12 \mathrm{~h}$. The prepared resins were injected into a glass-tubing mold ((Fiber Optic Center, Inc., Part \#: ST8100, New Bedford, MA)) and light-cured for $10 \mathrm{sec}$ at room temperature with a LED light curing unit (LED Curebox, Proto-tech, Portland, OR, USA) [23]. The polymerized samples were stored in the dark at room temperature for $48 \mathrm{~h}$ and 1 week in a vacuum oven in the presence of a drying agent at $37^{\circ} \mathrm{C}$. The resultant rectangular beam specimens $\left(1 \times 1 \times 15 \mathrm{~mm}^{3}\right)$ were used to determine the degree of conversion (DC), water sorption and solubility, and dynamic mechanical properties.

The DC was determined by using a LabRAM ARAMIS Raman spectrometer (LabRAM HORIBA Jobin Yvon, Edison, New Jersey) with a HeNe laser ( $\lambda=633 \mathrm{~nm}$, a laser power of $17 \mathrm{~mW}$ ) as an excitation source [15, 24]. The instrument conditions were: $200 \mu \mathrm{m}$ confocal hole, $150 \mu \mathrm{m}$ wide entrance slit, $600 \mathrm{gr} / \mathrm{mm}$ grating, and $10 \times$ objective Olympus lens. Data processing was performed using LabSPEC 5 (HORIBA Jobin Yvon). The samples were mounted on a computer-controlled, high-precision x-y stage. To determine the DC, spectra of the unpolymerized resins and rectangular beam samples were acquired over a range of $700-1800 \mathrm{~cm}^{-1}$. The change of the band height ratios of the aliphatic $\mathrm{C}=\mathrm{C}$ double bond peak at $1640 \mathrm{~cm}^{-1}$ and the aromatic $\mathrm{C}=\mathrm{C}$ at $1610 \mathrm{~cm}^{-1}$ (phenyl) in both the cured and uncured states was monitored and the DC calculated using the following equation based on the decrease in the intensity band ratios before and after light curing.

$$
D C(\%)=\left[1-\left(\mathrm{R}_{\text {cured }} / \mathrm{R}_{\text {uncured }}\right)\right] \times 100,
$$

where $\mathrm{R}=$ band height at $1640 \mathrm{~cm}^{-1} / \mathrm{band}$ height at $1610 \mathrm{~cm}^{-1}$. All experiments were carried out in triplicate and the results were averaged.

\subsection{Mass change, water sorption and solubility}

Rectangular beam specimens $\left(1 \times 1 \times 15 \mathrm{~mm}^{3} ; \mathrm{n}=3\right.$ in each group $)$ were stored in a desiccator at $23{ }^{\circ} \mathrm{C}$ for $1 \mathrm{~h}$ prior to weighing with a calibrated electronic balance (Mettler Toledo, XS 205 ; resolution of $0.01 \mathrm{mg})$. This drying cycle was repeated until a constant mass $\left(m_{l}\right)$ was obtained. After drying, the specimens were immersed in distilled water at $37^{\circ} \mathrm{C}$. The specimens were removed at fixed time intervals $(3,5,24,48,96,168$, and $240 \mathrm{~h})$, blotted to remove excess water, weighed $\left(m_{2}\right)$ and returned to the water. All the specimens were then removed from the water and placed in a vacuum oven containing a freshly dried silica gel at $37^{\circ} \mathrm{C}$ until a constant weight was achieved $\left(m_{3}\right)$ [15, 25-26]. The values (\%) for mass change $\left(W_{m c}\right)$, solubility $\left(W_{s u}\right)$, and water sorption $\left(W_{s p}\right)$ were calculated as

$$
\begin{aligned}
& W_{m c}(\%)=\left(m_{2}-m_{1}\right) / m_{1} \\
& W_{s u}(\%)=\left(m_{1}-m_{3}\right) / m_{1}
\end{aligned}
$$




$$
W_{s p}(\%)=W_{m c}(\%)+W_{s u}(\%)
$$

\subsection{Dynamic mechanical analysis (DMA)}

DMA is used to characterize the viscoelastic properties of materials as they are subjected to periodic loading under a range of temperatures. In this study, all DMA tests were performed using DMA Q800 (TA Instruments, New Castle, USA) with a three-point bending clamp. Rectangular beam specimens $\left(1 \times 1 \times 15 \mathrm{~mm}^{3}\right)$ were divided into two groups with five samples per group. The first group consisted of dry samples prepared as described under specimen preparation. These specimens were tested using a standard 3-point bending clamp. The test temperature was varied from 0 to $200{ }^{\circ} \mathrm{C}$ with a ramping rate of $3{ }^{\circ} \mathrm{C} / \mathrm{min}$ at a frequency of 1 $\mathrm{Hz}$. The second group consisted of wet samples, which had been dried as described previously and then stored in distilled water at $37^{\circ} \mathrm{C}$ for 5 days. These specimens were tested using a 3-point bending water-submersion clamp and thus, the specimens were tested while submerged in water. The test temperature was varied from 4 to $70{ }^{\circ} \mathrm{C}$ with a ramping rate of $3{ }^{\circ} \mathrm{C} / \mathrm{min}$ at a frequency of $1 \mathrm{~Hz}$. Samples can be heated up to $70^{\circ} \mathrm{C}$ using the 3-point bending water-submersion clamp. The properties measured under this oscillating loading are storage modulus $\left(\mathrm{E}^{\prime}\right)$ and $\tan \delta$. The $\mathrm{E}^{\prime}$ value represents the stiffness of a viscoelastic material and is proportional to the energy stored during a loading cycle. The ratio of loss modulus ( $\left.\mathrm{E}^{\prime \prime}\right)$ to storage modulus $\mathrm{E}^{\prime}$ is referred to as $\tan \delta$ (i.e., $\tan \delta=\mathrm{E}^{\prime \prime} / \mathrm{E}^{\prime}$ ). Five specimens of each material were measured and the results averaged.

The results were analyzed statistically using analysis of variance (ANOVA), together with Tukey's test at $\alpha=0.05$ (Microcal Origin Version 6.0, Microcal Software Inc., Northampton, MA).

\section{Results}

Table 1 shows the degree of conversion of the adhesive polymers. The DC for all adhesives was in the range of $85-92 \%$. As the number of ethylene glycol units in the monomer increased from 1.0 (EGDM) to 3 (TEGDMA), the DC increased from $85 \%$ to $91 \%$.

Mass change, water sorption and solubility of dentin adhesive polymers after storage in water at $37^{\circ} \mathrm{C}$ for 10 days are shown in Fig. 2 All the samples exhibited similar mass change behavior, i.e. a rapid increase in mass during the first $24 \mathrm{~h}$ of water immersion (Fig. 2a). The water sorption varied from a low of $6.7 \%$ for GlyT to a high of $9.9 \%$ for GlyD (Fig. 2b). Polymer solubility ranged from 0.3-1.4\% with the experimental adhesive EG exhibiting the greatest solubility (Fig. 2c).

Fig. 3 shows the average storage moduli measured using standard 3-point bending and 3point water-submersion at 37 (a) and $70{ }^{\circ} \mathrm{C}$ (b). The storage moduli of wet samples measured using the water submersion clamp were significantly lower than those of dry samples. Overall, experimental adhesives, EG, DEG, and TEG showed significantly lower ( $\mathrm{p}<0.05$ ) storage moduli under both dry and wet conditions at $37^{\circ} \mathrm{C}$ as compared to the control, $\mathrm{C} 0$. At $70{ }^{\circ} \mathrm{C}$ and under wet conditions, the storage moduli of GlyD (581 MPa) and GlyT $(814 \mathrm{MPa})$ were significantly greater $(\mathrm{p}<0.05)$ than that the control C0 $(267 \mathrm{MPa})$.

In the rubbery region, the average storage moduli of GlyD and GlyT (96 and $234 \mathrm{MPa}$, respectively) were significantly greater $(\mathrm{p}<0.05)$ than that of the control adhesive $(\mathrm{C} 0: 31$ MPa) (Fig. 4). 
Fig. 5 shows representative tan delta curves of dried adhesive polymers as a function of temperature. All samples showed a wide range of widths of the $\tan \delta$ curves. The $\tan \delta$ peak height of $\mathrm{C} 0$ adhesive polymer was the highest, while GlyT exhibited the lowest.

\section{Discussion}

This work investigated the influence of the chemical structure of methacrylate monomers most commonly used in dentin adhesives on the degree of conversion, water sorption, solubility, and dynamic mechanical properties. EGDM, DEGDM, TEGDMA, GDM, and GTM have been used as a co-monomer. These monomers are structurally analogous to each other and were incorporated into the control adhesive (composed of BisGMA and HEMA with a mass ratio of 55/45 wt $\%$ ). The photoinitiator system and the light-induced photoinitiation process were consistent for all of the resin systems.

Because water is always present in the mouths of healthy individuals, it is important to understand how the properties of dentin adhesives are influenced by water. Water may promote a variety of chemical and physical processes that create biological concerns as well as produce deleterious effects on the structure and function of the polymer matrix itself. Therefore, the study of water sorption, solubility and mechanical behavior under wet conditions is relevant to understanding the performance of adhesive polymers in the wet, oral environment. As revealed in Table 1 and Fig. 2, as the number of ethylene glycol units in the monomer increased from 1.0 (EGDM) to 3 (TEGDMA), DC, and water sorption increased. These results may be attributed to the enhanced hydrophilicity and flexibility of the system because of an increase in the number of ethylene glycol units. Ethylene glycol is a linear aliphatic unit and is hydrophilic by nature. Water sorption is dependent on the crosslink density of the polymer and the potential for hydrogen bonding and polar interactions [26-27]. As compared to GlyD, GlyT adhesive containing GTM which is structurally analogous to GDM with a glycerol moiety, realized significantly $(\mathrm{p}<0.05)$ less water sorption $(6.7 \%)$. GTM has a trimethacrylate that can contribute to the increased crosslink density, and no hydroxyl group which is related to less potential for hydrogen bonding; these factors contribute to the low water sorption (Fig. 2b). The decreased water sorption of GlyT adhesive relative to the other resin systems is consistent with the DMA results, which showed that the GlyT adhesive had the highest crosslink density.

Generally, the water sorption decreases with the increase of crosslinking and increases with an increase in the hydrophilicity of the polymer network. When the crosslinking and hydrophilicity both increase previous results of water sorption showed that the hydrophilicity of the polymer network is a more important factor than the crosslinking density [13]. This is accordance with the current findings, GlyD adhesive containing GDM which has the highest hydrophilicity among monomers studied here, showed the highest water sorption.

When adhesive samples are immersed in water, some of the components, such as unreacted monomers, are dissolved and leached from the samples. This results in loss of weight and can be measured as solubility. In Fig. 2c, the lowest solubility was observed in $\mathrm{C} 0$ and the highest in EG. This result could be explained by the DC as well as differences in the relative molecular size of the monomers. The $\mathrm{CO}$ has the highest $\mathrm{DC}$ and relatively higher content of BisGMA. As shown in Table 1, BisGMA is a relatively large molecule which is not readily leached by water. The lower solubility of the control adhesive formulation is attributed to the higher DC and the increase in the concentration of the bulky BisGMA.

Because DMA gives information on the relaxation of molecular motions which are sensitive to structure and variation in stiffness of materials, it can be used to provide information on 
the properties of polymer networks, such as storage modulus and glass transition. In this study, although the DMA tests were performed using both standard 3-point bending and 3point bending water-submersion methods, it is anticipated that the results with the watersubmersion clamp are more representative of the behavior of the polymer in the wet environment of the mouth. The results (Fig. 3) indicate that the storage moduli of wet samples measured using the water-submersion clamp were significantly lower than those of the dry samples. This difference may be due to plasticization of the polymers in the wet environment. When a polymer is placed in water, hydrogen bonds that form between water and the polar groups $(-\mathrm{OH},-\mathrm{C}=\mathrm{O}$, etc $)$ of the polymer network disrupt interchain interaction, altering the molecular structure and increasing the segmental mobility of polymer chain segments. These changes are reflected as a reduction in the mechanical properties. The plasticization is attributed to the increasing free volume provided as the water swells the polymer and disrupts polymer-polymer hydrogen bonds. It is interesting to note that, although the storage moduli of wet GlyD and GlyT adhesives measured using the water submersion clamp at $37^{\circ} \mathrm{C}$ (Fig. 3a) were lower than that of the corresponding wet $\mathrm{C} 0$, they were significantly greater $(\mathrm{p}<0.05)$ at $70{ }^{\circ} \mathrm{C}$ (Fig. 3b). These results suggest better performance of the wet GlyD and GlyT adhesives as compared to the control at high temperature. The results also imply limitations in terms of the incorporation of the rigid, bulky BisGMA into the polymer network of the control adhesive [28]. GlyD and GlyT showed significantly higher rubbery moduli than the control (Fig. 4).

The storage moduli of all the samples showed a gradual decrease with increasing temperature. Near the glass transition temperature, storage moduli decrease drastically. As heating continues, all the samples reach the rubbery plateau, in which storage modulus is insensitive to further increase in temperature and the molecular chains are highly mobile. The storage moduli of the samples in the rubbery region were determined by taking the value at the inflection point of the plateau.

The modulus value in the rubbery region has been related to the crosslink density of the material [29]. The significantly higher rubbery moduli indicate that GlyD and GlyT adhesives give the higher crosslink density, suggesting that the structure of the co-monomer with a higher functionality (like GTM) and a hydroxyl group that can form a quasi-network hydrogen bond structure (like GDM) has a large influence on the rubbery modulus. In GlyT adhesive containing GTM, the use of trimethacrylate monomer increases the mean functionality of the monomer mixture and increases the average crosslink density of the network.

The broad $\tan \delta$ curves for all the samples tested here (Fig. 5) indicate that the polymer networks are heterogeneous with glass transition occurring over a broad range of temperature. These results may be attributed to the fact that the polymerization of multifunctional monomers produces networks with highly heterogeneous environments, i.e. regions that are highly crosslinked and regions with limited crosslinking; these features lead to a very broad distribution of mobilities or relaxation times [30-31]. All the experimental adhesives $\left(53 \sim 118{ }^{\circ} \mathrm{C}\right)$ exhibited wider $\tan \delta$ curves than that of the control, $\mathrm{C} 0\left(32^{\circ} \mathrm{C}\right)$ (Fig. 5). This observation suggests that the heterogeneity of the polymer network increases as the bulky BisGMA is partially replaced by the monomer with low molecular weight or monomer with high functionality. GlyT adhesive containing GTM showed the broadest $\tan \delta$ curve, indicating the most heterogeneous structure. The control adhesive showed the narrowest $\tan \delta$ curve and thus, the most homogeneous network.

The intensity of the maximum tan $\delta$ peak reflects the extent of mobility of the polymer chain segments at this temperature [32]. Higher values of $\tan \delta$ peak indicate higher energy loss and more viscous behavior, whereas lower $\tan \delta$ values indicate less viscous and higher 
elastic behavior [33]. All the experimental adhesives showed lower $\tan \delta$ peak heights than that of the $\mathrm{C} 0$. This result may be explained by the fact that the addition of a third monomer with a multifunctional group and/or a small molecular weight between crosslinks is thought to produce a higher crosslink density and correspondingly a reduction in the intensity of the tan $\delta$ peak. Typically, an increase in crosslink density results in an increase in the thermal/ mechanical properties as the mobility of the copolymer becomes increasingly restricted. However, the relationship between crosslink density and thermal/mechanical properties is not straightforward. Based on the type of crosslinking monomers the copolymerization effect may in some cases reverse the trends expected based on the crosslinking effect [30].

\section{Conclusions}

In this work, an overall perspective of the effect of the chemical structure of methacrylatebased monomers on the degree of conversion, water sorption, solubility, dynamic mechanical properties in the presence and absence of water, crosslink density and heterogeneity of polymer network has been examined. The selection of $c o$-monomers used in dentin adhesives exerted considerable influence on the properties. For EGDM, DEGDM, TEGDMA as a co-monomer, the DC, mass change, and water sorption of the experimental adhesives increased as the number of ethylene glycol units in the monomer increased. Although the structures of GDM, EGDM and DEGDM are similar, the adhesive containing GDM showed higher storage modulus in both dry and wet samples as compared to adhesives containing EGDM or DEGDM. In addition, the rubbery moduli of GlyD and GlyT adhesives were found to be significantly higher than that of $\mathrm{C} 0$, indicating their higher crosslink density. However, the heterogeneity of the polymer network increases as the rigid, bulky BisGMA is partially replaced by the third monomers tested here. These results highlight the complexity of the relationship between crosslink density and thermal/ mechanical properties, e.g. increased crosslink density may be accompanied by a sacrifice in homogeneity of the polymer network structure.

\section{Acknowledgments}

This investigation was supported by Research Grants: R01DE14392-09 and R01DE01492-08S1 (PI: Spencer) from the National Institute of Dental and Craniofacial Research, National Institutes of Health, Bethesda, MD 20892.

\section{References}

1. Beazoglou T, Eklund S, Heffley D, Meiers J, Brown LJ, Bailit H. Economic impact of regulating the use of amalgam restorations. Public Health Rep. 2007; 122:657-63. [PubMed: 17877313]

2. Murray PE, Windsor LJ, Smyth TW, Hafez AA, Cox CF. Analysis of pulpal reactions to restorative procedures, materials, pulp capping, and future therapies. Crit Rev Oral Biol Med. 2002; 13:509_ 20. [PubMed: 12499243]

3. Simecek JW, Diefenderfer KE, Cohen ME. An evaluation of replacement rates for posterior resinbased composite and amalgam restorations in US Navy and Marine Corps recruits. Journal of the American Dental Association. 2009; 140:200-9. [PubMed: 19188417]

4. Bernardo M, Luis H, Martin MD, Leroux BG, Rue T, Leitao J, et al. Survival and reasons for failure of amalgam versus composite posterior restorations placed in a randomized clinical trial. Journal of the American Dental Association. 2007; 138:775-83. [PubMed: 17545266]

5. Levin L, Coval M, Geiger SB. Cross-sectional radiographic survey of amalgam and resin-based composite posterior restorations. Quintessence International. 2007; 38:511-4. [PubMed: 17625635]

6. Soncini JA, Maserejian NN, Trachtenberg F, Tavares M, Hayes C. The longevity of amalgam versus compomer/composite restorations in posterior primary and permanent teeth: findings From the New England Children's Amalgam Trial. J Am Dent Assoc. 2007; 138:763-72. [PubMed: 17545265] 
7. Hansel C, Leyhausen G, Mai UE, Geurtsen W. Effects of various resin composite (co)monomers and extracts on two caries-associated micro-organisms in vitro. J Dent Res. 1998; 77:60-7. [PubMed: 9437400]

8. Leinfelder KF. Do restorations made of amalgam outlast those made of resin-based composite? Journal of the American Dental Association. 2000; 131:1186-7. [PubMed: 10953536]

9. Santerre JP, Shajii L, Leung BW. Relation of dental composite formulations to their degradation and the release of hydrolyzed polymeric-resin-derived products. Crit Rev Oral Biol Med. 2001; 12:13651. [PubMed: 11345524]

10. Kleverlaan CJ, Feilzer AJ. Polymerization shrinkage and contraction stress of dental resin composites. Dent Mater. 2005; 21:1150-7. [PubMed: 16040118]

11. Roulet JF. Benefits and Disadvantages of Tooth-coloured Alternatives to Amalgam. J Dent. 1997; 25:459-73. [PubMed: 9604577]

12. Breschi L, Mazzoni A, Ruggeri A, Cadenaro M, DiLenarda R, DeStefano Dorigo E. Dental adhesion review: Aging and stability of the bonded interface. Dent Mater. 2007 in press.

13. Ferracane JL. Hygroscopic and hydrolytic effects in dental polymer networks. Dental Materials. 2006; 22:211-22. [PubMed: 16087225]

14. Spencer $P$, Wang Y. Adhesive phase separation at the dentin interface under wet bonding conditions. J Biomed Mater Res. 2002; 62:447-56. [PubMed: 12209931]

15. Park J, Ye Q, Topp E, Misra A, Spencer P. Water sorption and dynamic mechanical properties of dentin adhesives with a urethane-based meltifunctional methacrylate monomer. Dent Mater. 2009; 25:1569-75. [PubMed: 19709724]

16. Ye Q, Spencer P, Wang Y, Misra A. Relationship of solvent to the photopolymerization process, properties, and structure in model dentin adhesives. J Biomed Mater Res A. 2007; 80:342-50. [PubMed: 17001655]

17. Van Landuyt KL, Snauwaert J, De Munck J, Peumans M, Yoshida Y, Poitevin A, et al. Systematic review of the chemical composition of contemporary dental adhesives. Biomaterials. 2007; 28:3757-85. [PubMed: 17543382]

18. Park J, Ye Q, Topp E, Spencer P. Enzyme-catalyzed hydrolysis of dentin adhesives containing a new urethane-based trimethacrylate monomer. J Biomed Mater Res Part B-Appl Biomater. 2009; 91B:562-71. [PubMed: 19582843]

19. Moszner N, Salz U, Zimmerman J. Chemical aspects of self-etching enamel-dentin adhesives: A systematic review. Dental Materials. 2005; 21:895-910. [PubMed: 16038969]

20. Moszner N, Salz U. Recent developments of new components for dental adhesives and composites. Macromolecular Materials and Engineering. 2007; 292:245-71.

21. Park J, Ye Q, Topp EM, Kostoryz EL, Wang Y, Kieweg SL, et al. Preparation and properties of novel dentin adhesives with esterase resistance. J Appl Polym Sci. 2008; 107:3588-97.

22. Park J, Ye Q, Topp E, Misra A, Kieweg SL, Spencer P. Effect of Photoinitiator system and water content on dynamic mechanical properties of a light-cured BisGMA/HEMA Dental Resin. J Biomed Mater Res. 2010; 93A:1245-51.

23. Park J, Ye Q, Topp EM, Misra A, Spencer P. Water sorption and dynamic mechanical properties of dentin adhesives with a urethane-based multifunctional methacrylate monomer. Dental Materials. 2009; 25:1569-75. [PubMed: 19709724]

24. Park J, Ye Q, Topp EM, Lee CH, Kostoryz EL, Misra A, et al. Dynamic mechanical analysis and esterase degradation of dentin adhesives containing a branched methacrylate. J Biomed Mater Res Part B: Appl Biomater. 2009; 91B:61-70. [PubMed: 19358261]

25. Sideridou I, Karabela M, Vouvoudi E. Dynamic thermomechanical properties and sorption characteristics of two commercial light cured dental resin composites. Dent Mater. 2008; 24:73743. [PubMed: 17889316]

26. Zhang Y, Xu J. Effect of immersion in various media on the sorption, solubility, elution of unreacted monomers, and flexural properties of two model dental composite compositions. J Mater Sci: Mater Med. 2008; 19:2477-83. [PubMed: 18253815]

27. Ortengren U, Wellendorf H, Karlsson S, Ruyter IE. Water sorption and solubility of dental composites and identification of monomers released in aqueous environment. Journal of Oral Rehabilitation. 2001; 28:1106-15. [PubMed: 11874509] 
28. Jancar J, Wang W, Dibenedetto AT. On the heterogeneous structure of thermally cured bis-GMA/ TEGDMA resins. J Mater Sci: Mater Med. 2000; 11:675-82. [PubMed: 15348072]

29. Shi S, Nie J. Investigation of 3,4-methylenedioxybenzene methoxyl methacrylate as coinitiator and comonomer for dental application. J Biomed Mater Res Part B-Appl Biomater. 2007; 82B:487-93. [PubMed: 17285604]

30. Kannurpatti AR, Anseth JW, Bowman CN. A study of the evolution of mechanical properties and structural heterogeneity of polymer networks formed by photopolymerizations of multifunctional (meth)acrylates. Polymer. 1998; 39:2507-13.

31. Cook WD, Scott TF, Quay-Thevenon S, Forsythe JS. Dynamic mechanical thermal analysis of thermally stable and thermally reactive network polymers. J Appl Polym Sci. 2004; 93:1348-59.

32. Hill DJT, Perera MCS, Pomery PJ, Toh HK. Dynamic mechanical properties of networks prepared from siloxane modified divinyl benzene pre-polymers. Polymer. 2000; 41:9131-7.

33. McCabe JF, Arikawa H. Rheological Properties of Elastomeric Impression Materials Before and During Setting. J Den Res. 1998; 77:1874-80. 


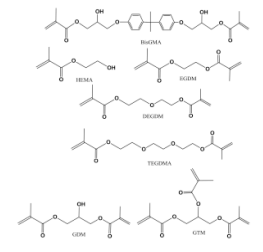

Fig. 1.

Chemical structures of methacrylate monomers used in this study. 
(a)

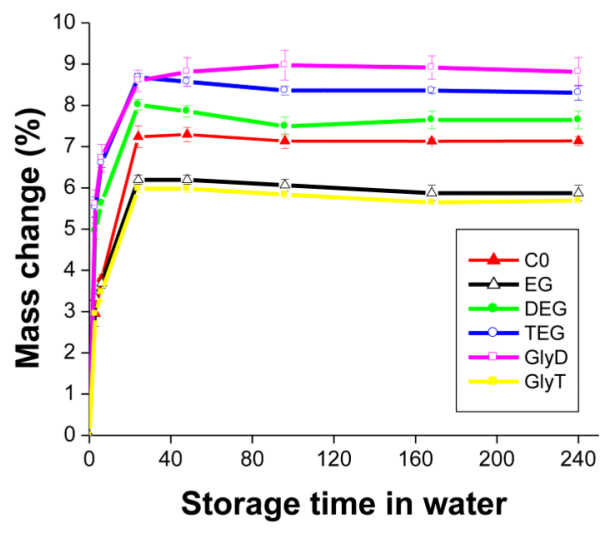

(b)

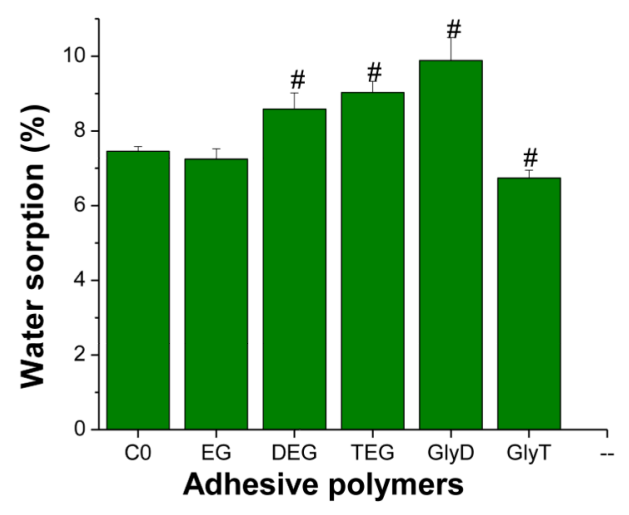

(c)

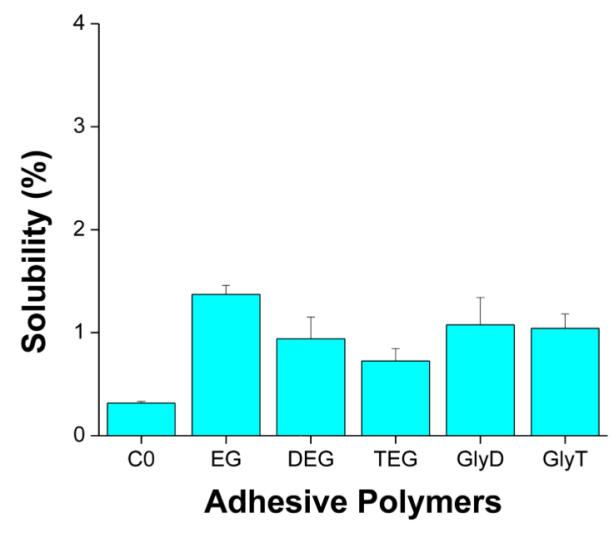

Fig. 2.

Mass change (a), water sorption (b) and solubility (c) of dentin adhesive polymers as a function of storage time in water. Three specimens were prepared for each adhesive polymer and immersed in distilled water at $37{ }^{\circ} \mathrm{C}$ at fixed time intervals. Symbols: $\mathrm{C} 0$ is composed of BisGMA and HEMA with a mass ratio of 55/45. For EG, DEG, TEG, GlyD, and GlyT, BisGMA was partially replaced by the model monomer, EGDM, DEGDM, TEGDMA, GDM, GTM, respectively. Values are mean (error bar: standard deviation) for $\mathrm{n}=3$ in each group. \#Significantly $(\mathrm{p}<0.05)$ different from dry $\mathrm{C} 0$. 
(a)

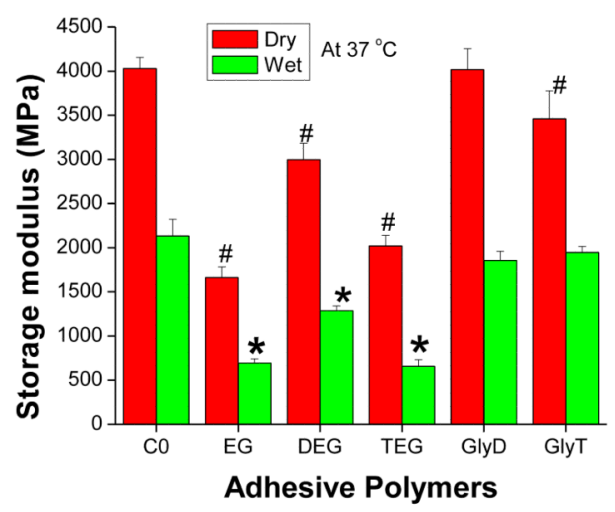

(b)

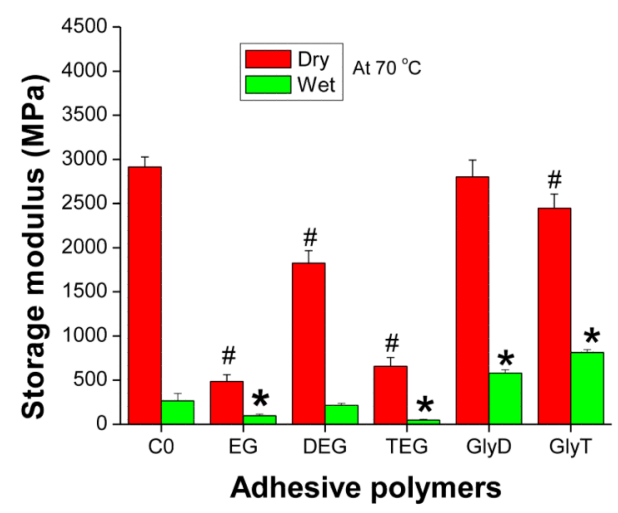

Fig. 3.

The storage moduli of adhesive polymers at $37{ }^{\circ} \mathrm{C}$ (a) and $70{ }^{\circ} \mathrm{C}$ (b). Values are mean (error bar: standard deviation) for $\mathrm{n}=5$ in each group. \#Significantly $(\mathrm{p}<0.05)$ different from dry $\mathrm{C} 0$; *Significantly $(\mathrm{p}<0.05)$ different from wet $\mathrm{C} 0$. 


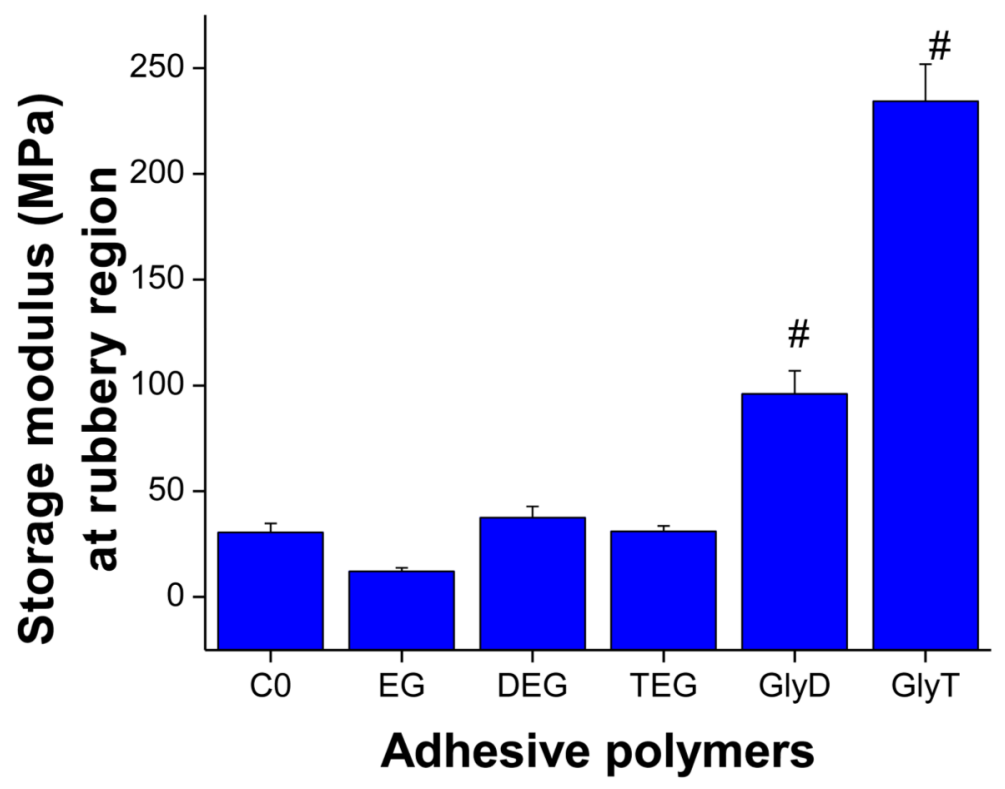

Fig. 4.

The storage moduli of adhesive polymers in the rubbery region. Values are mean (error bar: standard deviation) for $n=5$ in each group. The storage moduli in the rubbery region were determined by taking the value at the inflection point of the plateau. \#Significantly $(\mathrm{p}<0.05)$ different from dry $\mathrm{C} 0$. 


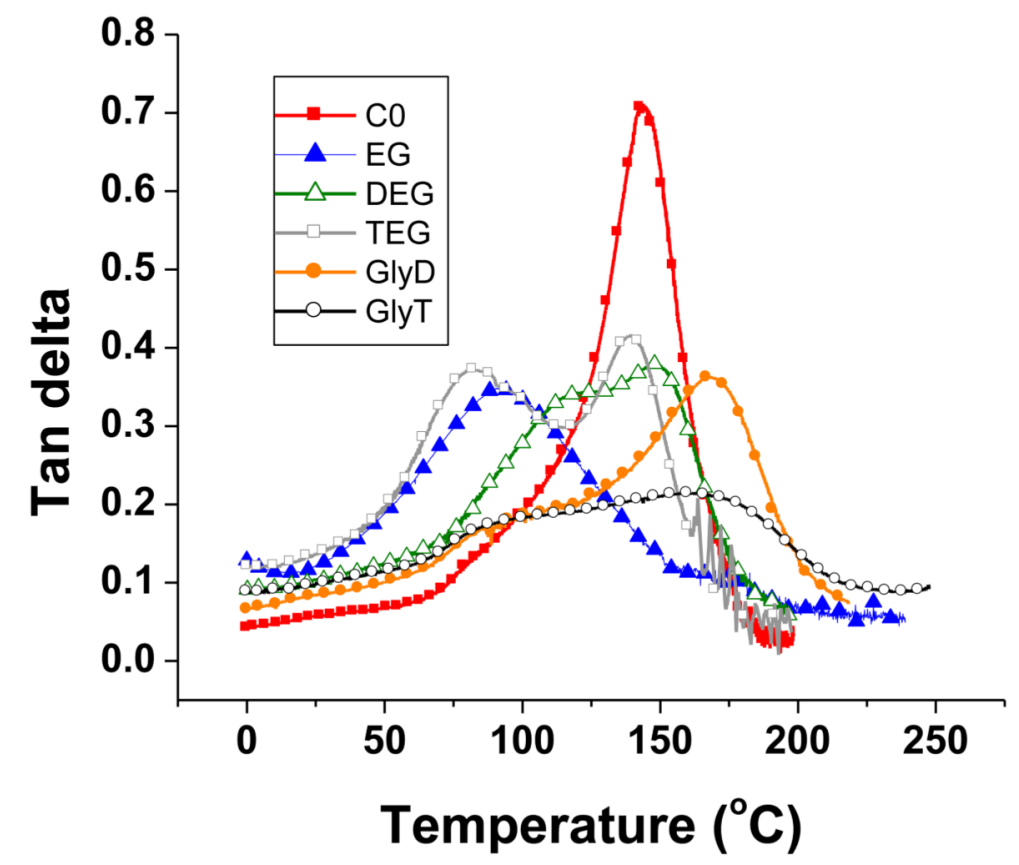

Fig. 5.

Representative tan delta curves of dried adhesive polymers. The intensity (height) of the tan delta peak reflects the extent of mobility of polymer chain segments at this temperature. The width of the tan delta peak reflects the heterogeneity of the polymer network. 
